\title{
Optical T-Bench Method of Measuring Longitudinal Spherical Aberration
}

\author{
Francis E. Washer
}

\begin{abstract}
A method of measuring longitudinal spherical and chromatic aberration by visual means is described. The method employs an especially constructed optical T-bench equipped with nodal slide and an angle-measuring telescope. The underlying theory of the method is presented, together with a brief description of the apparatus used. The results of measurement on a few typical lenses and an analysis of the sources of error are included.
\end{abstract}

\section{Introduction}

The determination of longitudinal spherical aberration is frequently required during the course of the measurement of the optical characteristics of photographic objectives. While many methods have been developed that are capable of yielding this information, it, nonetheless, seems worth while to describe a method that has been in use at the National Bureau of Standards since 1943. This is an indirect method, in that the lens is used to collimate the light from a point source located in the focal plane, and the angular deviations of adjacent beams from parallelism are measured. The determination of the longitudinal spherical aberration is based on the analysis of these angular deviations. At the time of inception it was necessary to develop a simple, rapid method of evaluating the longitudinal spherical aberration of reflector sight lenses. ${ }^{1}$ In connection with the development of this rapid method, the present more accurate procedure was developed for the purpose of checking the results.

Early work was done with relatively simple apparatus that was rather unstable. The apparent worth of the method was, however, sufficiently high as to warrant the construction of new equipment in order that a higher degree of accuracy could be obtained. The resulting equipment consisting of the optical $T$-bench and a new nodal slide is shown in figures 3 and 4.

\section{Theory of the Method}

When a lens is affected with longitudinal spherical aberration, the effect can be described most simply by considering it as change in positions of the focal point for the various annular zones of the lens. For an ideal lens the focus is a point on the axis in the image space through which pass all rays of light that are initially parallel to the axis in the object space prior to incidence on the front surface of the lens. If the lens is reversed and a point source of light placed at the focus, the light incident on the back surface of the lens will emerge as a parallel beam of light concentric with the lens axis. This condition is shown schematically in figure 1, where

1 F. E. Washer, An instrument for measuring longitudinal spherical aberration of lenses, J. Research NBS 43, 137 (1949) RP2015.

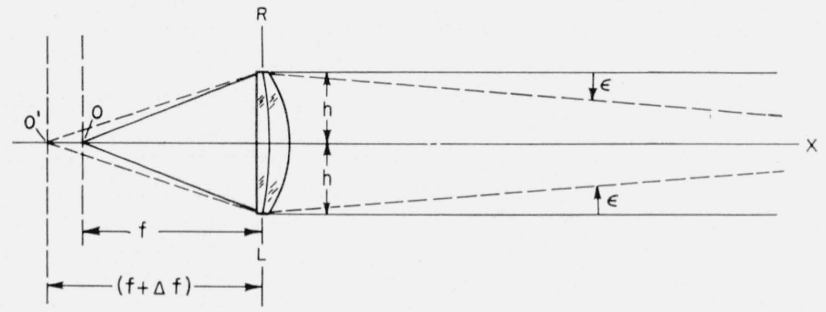

Figure 1. Schematic drawing of a lens showing light incident on the lens from a point source on the axis at $O$.

For $\mathrm{O}$ located at the focus, the emergent beam is parallel to the lens axis. When $\mathrm{O}$ moves by amount, $\Delta f$, to $\mathrm{O}^{\prime}$, the emergent beam is convergent, and a ray located at zone height, $h$, is deviated through the angle, $\epsilon$.

light from the point source, $\mathrm{O}$, is incident on the lens at height $h$ and emerges parallel to the axis OX. Let the point source, $\mathrm{O}$, be moved by amount $\Delta f$, to $\mathrm{O}^{\prime}$. If $\mathrm{O}^{\prime}$ is farther from the lens than $\mathrm{O}$, the emergent beam is convergent. For a ray incident at height $h$, the emergent ray will deviate from parallelism with the axis by the angle $\epsilon$. It can be shown that

$$
\epsilon=\frac{\Delta f h}{f^{2}+f \Delta f},
$$

where $f$ is the equivalent focal length of the lens. For known values of $\epsilon$, the value of $\Delta f$ can be determined to a close approximation from the relation

$$
\Delta f=\frac{\epsilon f^{2}}{h}\left(1+\frac{\Delta f}{f}\right)
$$

For $\Delta f$, very small compared with $f$, the above relation may be written

$$
\Delta f=\frac{\epsilon}{h} f^{2} .
$$

It is clear that only a 1-percent error is introduced into the determination of $\Delta f$ for a value of $\Delta f=0.01 f$. This can be further reduced by inserting the approximate value of $\Delta f$ obtained from eq (3) into eq (2) and redetermining $\Delta f$. However, for most practical purposes the value of $\Delta f$ computed from eq (3) is satisfactory.

If the lens shown in figure 1 is affected with longitudinal spherical aberration, rays of light from the point source at 0 incident on the lens at varying zone heights, $h$, will deviate from parallelism with the axis 
by varying amounts, $\epsilon$. If the various values of $\epsilon$ are plotted as a function of $h$, a curve such as No. 1 in figure $2, \mathrm{~A}$, will result. For this curve, the variation of $\epsilon$ with $h$, arises from a combination of two effects: (1) Out-of-focus effect, and (2) angular spherical aberration or parallax resulting from longitudinal spherical aberration of the lens. The two effects can be separated quite easily, as out-of-focus effect produces a variation of $\epsilon$ proportional to $h$, which plots as a straight line of constant slope passing through the zero point of the graph. This is shown by curve 3 in figure 2, A. The nonlinear portion of the curve arises from angular spherical aberration. On subtracting the abscissas of curve 3 from those of curve 1 for corresponding values of $h$, the resulting values of $\epsilon$ are those produced by the angular spherical aberration of the lens; this is shown as curve 2 in figure $2, \mathrm{~A}$.
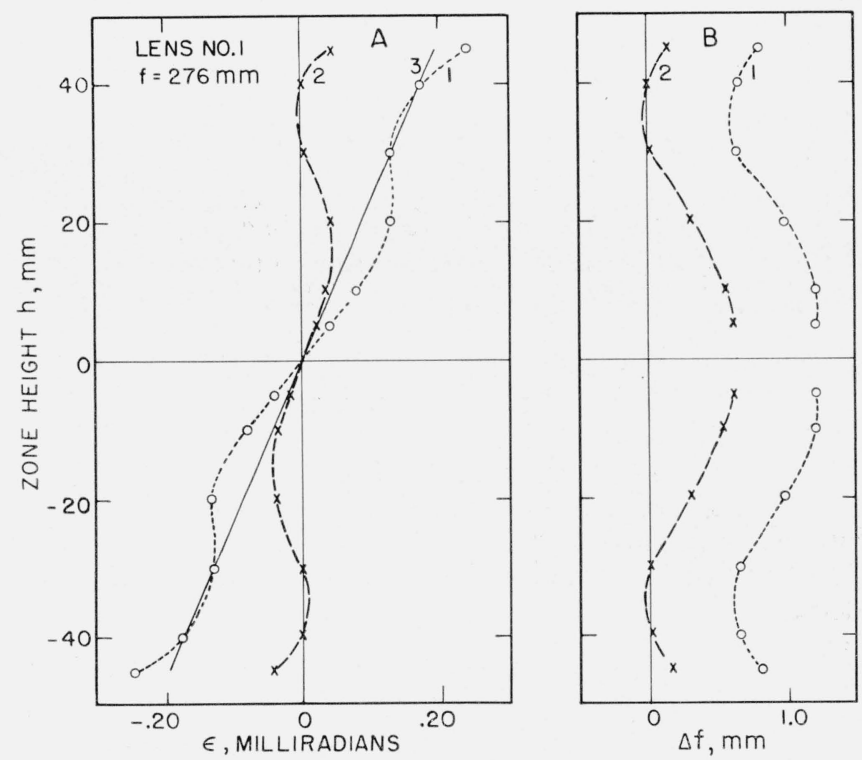

Figure 2. Parallax angle $\epsilon$ versus $h$, and $\Delta f$ versus $h$, for $a$ typical lens.

A. Curve 1 shows the variation of $\epsilon$ with $h$ when the lens has longitudinal A. Curve 1 shows the variation of $\epsilon$ with $h$ when the lens has longitudinal shows the variation of $\epsilon$ arising from out-of-focus effect alone of $\Delta \mathrm{f}=0.67 \mathrm{~mm}$. shows the variation of $\epsilon$ arising from out-of-focus effect alone of $\Delta \mathrm{f}=0.67 \mathrm{~mm}$.
Curve 2 shows the angular spherical aberration alone (the difference between Curve 2 shows the angular spherical aberration alone (the difference between 1 and 3 ).

B. Curve 1 shows values of $\Delta \mathrm{f}$ computed before making the correction for outof-focus effect. Curve 2 shows values of $\Delta$ f after making correction for an out-offocus effect of $0.67 \mathrm{~mm}$. Curve 2 is also the longitudinal spherical aberration plotted with respect to the plane of best focus for zone height, $h=40 \mathrm{~mm}$.

When the value of $f$ is known and the values of $\epsilon$ as a function of $h$ have been measured for the condition of point source located on the lens axis and in the vicinity of the focal point, the values of $\Delta f$ can be computed with the aid of eq (3). When the values of $\Delta f$ are plotted as a function of $h$, the resulting curve shows the longitudinal spherical aberration. If the point source is not at the true focal point, the entire curve is displaced along the axis by an amount that is readily obtained from the graph or from the computed values of $\Delta f$.

In figure $2, \mathrm{~B}$, curve 1 shows the values of $\Delta f$ obtained using the same values of $\epsilon$ shown in curve 1 of figure $2, \mathrm{~A}$. It is clear that the entire curve is dis- placed from the zero line of abscissas; this indicates that the target did not lie in the plane of best focus for any zone of the lens. When the adjusted values of $\epsilon$ (plotted as curve 2 in fig. 2, A) are used in determining the values of $\Delta f$, the result is as shown in curve 2 of figure $2, \mathrm{~B}$; for this condition of focus, the target would lie in the focal plane of the zone for $h=40 \mathrm{~mm}$.

\section{Method of Measurement}

In order to measure the longitudinal spherical aberration of a lens by measuring the variations in parallax in the emergent beam, it is necessary to use equipment capable of making accurate measurements of parallax angle and zone radius $h$. The optical T-bench, shown in figure 3, was developed at this Bureau for use in making such measurements. It consists of two optical benches mounted at right angles to one another in the form of a $T$ on a strong: metal table. The lens under test is mounted on the nodal slide, as shown, with the target and illuminating system mounted on a separate bench slide as indicated. The viewing telescope is mounted on a movable slide located on the T-bench. The telescope is so arranged that its line of sight is approximately normal to the bench ways upon which its base slide can move. The pointing of the telescope is done with micrometers near the ocular end, which produce a small rotation about effective horizontal and vertical axes located in the flexure plate mounting near the objective end of the telescope. The change in pointing caused by a movement of the horizontal micrometer of one scale division is approximately 5.8 sec of arc. (The accurate calibration factor is 0.0283 milliradian per scale division.) In reading the micrometer, the value of the setting to the nearest one-tenth of a scale division can readily be made.

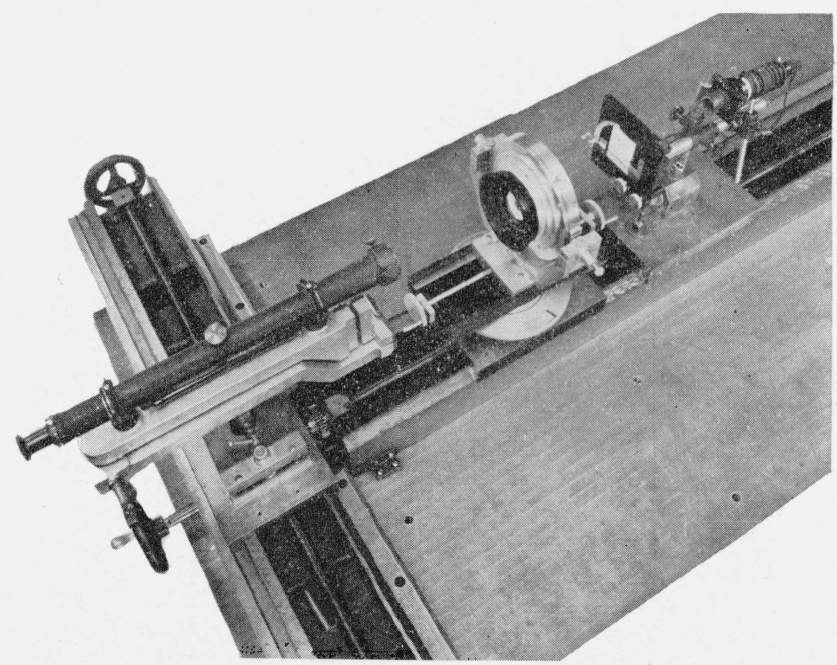

Figure 3. Arrangement of apparatus on optical T-bench for determination of longitudinal spherical aberration.

The lens under test is mounted in the nodal slide in the center of the picture. The target reticle and illuminating system are shown on the movable slide to the right of the nodal slide. The viewing telescope, equipped with diaphragm over the objective, is shown mounted on the transverse nodal slide in the left portion of the photograph. 
In preparing to measure the longitudinal spherical aberration, the lens is so positioned on the nodal slide that its rear nodal point coincides with the axis of rotation of the nodal slide. The axis of the lens under test is brought into parallelism with the bench ways, and the illuminated target is placed at the rear focal point of the lens. The positioning of the target at the focal point of the lens is done with the aid of the viewing telescope, which is itself set at infinity focus. The level of lens axis, target, and center of the viewing telescope object are adjusted so that all lie in approximately the same plane, which is parallel to the plane defined by the surfaces of the two bench ways.

The telescope objective is now covered with a diaphragm having a small central aperture, which is centered with respect to the telescope objective. When an observer looks through the telescope, he sees the image of an illuminated target (either a cross or pinhole pattern) superimposed on the cross hairs in the ocular of the viewing telescope. When the telescope is moved transversely by moving the slide upon which it is mounted, the image of the reticle will either stay on the cross hairs of the ocular or move toward one side of the visual field or the other. In the event of movement of the image, it can be brought again into coincidence with the cross hairs by appropriate movement of the transverse micrometer. The angular movement thus noted is a measure of the change in direction of a small circular beam of light emergent from a given area of the lens under test from the direction of a similar beam from another given area of the lens and lying along the same diameter.

It is a simple matter to select a given size of diaphragm opening, small in comparison with the area of the lens under test, and to select a series of steps so that measurements of the deviation of these successive small emergent beams can be made for an entire diameter of the lens. If the lens has been properly focused, and the telescope so moves that it always remains parallel to itself, the angular deviations noted arise from parallax (or angular spherical aberration) in the lens under test. The bench ways are so made that the telescope does maintain this condition of remaining parallel to itself at the various positions so that possible errors from this source can be regarded as negligible.

The scale on the bench carrying the telescope is used in making the successive settings at selected intervals. These settings are recorded, and the difference of successive bench scale readings from that one in the central position is recorded as $h$, the zone height. The micrometer readings for the successive pointings are taken for each value of $h$, and their differences from that one in the central position are recorded as $\epsilon$ 's. It is, of course, necessary to make a careful determination of the central position. This is usually done at the start of the experiment by noting the total range of transverse movement, throughout which the image of the illuminated target remains visible in the telescope ocular to the observer. These end points are noted, and a point midway between them is accepted as the center of coordinates.

Although it is believed that the possible deviations of the line of sight with movement of the telescope on its slide are negligible, it is presently the custom to avoid all possibility of error from this source by using an arrangement such as that shown in figure 4 . Here the telescope slide remains fixed, and the scanning across the aperture of the lens under test is accomplished by moving a slide carrying an appropriately mounted pentaprism. The deviation of the beam of light by the pentaprism is not changed by small rotations of the pentaprism about its vertical axis, which might be caused by small rotations of the carrying slide as it moves along the bench ways.

It is clear, then, that with this arrangement of apparatus it is possible to measure the values of $\epsilon$ as a function of $h$ in the emergent beam of collimated light from a lens. These values can be used to determine the values of the longitudinal spherical aberration with the aid of eq (3).

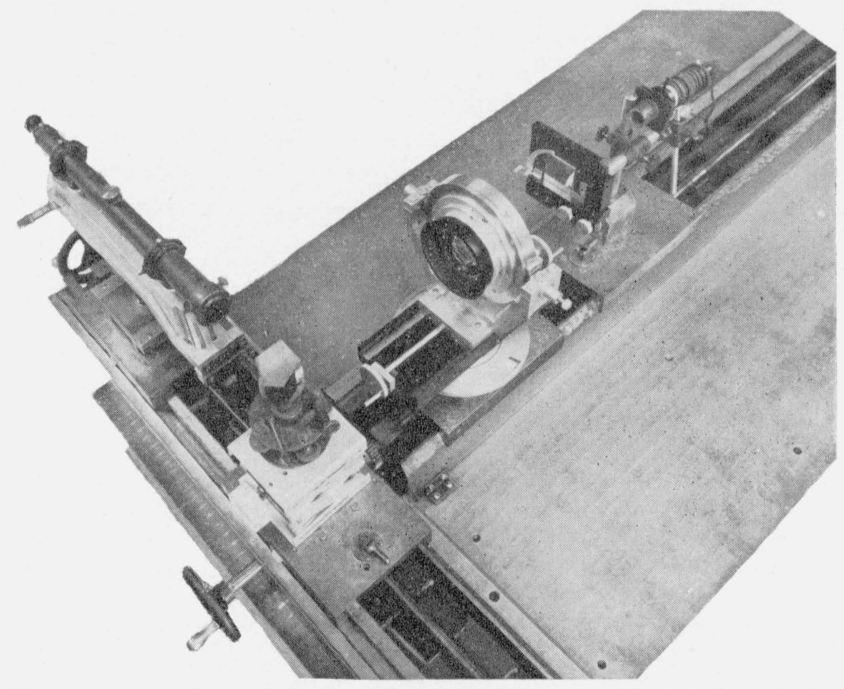

Figure 4. Arrangement of apparatus on optical T-bench for determination of longitudinal spherical aberration.

This arrangement differs from that shown in figure 3 in that a pentaprism has been placed on a movable slide on the transverse bench to eliminate transverse motion of the telescope.

\section{Results of Measurement}

This method of measuring longitudinal spherical aberration has been successfully used for several years at the Bureau for lenses having a wide range of focal lengths. In the succeeding sections, the results for a few typical lenses are given.

\subsection{Photographic Objective Having a Focal Length of 150 Millimeters}

\section{a. Effect of Target Displacement Along Axis}

Although there is no occasion to doubt the validity of the relations expressed in eq (1) and (3), it is nonetheless of interest to report the results of an experiment that confirms these relations and simultaneously puts to rest any lingering doubts concerning the proper sign of $\Delta f$. In addition, considerable 
information is gained on the probable accuracy and limitations of this method of determining longitudinal spherical aberration.

The lens selected for measurement was a photographic objective, designated lens 2 , having a nominal focal length of 6 in. and a maximum aperture of $f / 6.3$. The measured value of the equivalent focal length was $152.4 \mathrm{~mm}$, which means that the maximum value of $h$ (the half-diameter of the aperture) was $12.1 \mathrm{~mm}$. The arrangement of apparatus was as shown in figure 4 . The diameter of the diaphragm opening placed over the telescope was $2.0 \mathrm{~mm}$.

The viewing telescope was first focused for infinity for the condition of no diaphragm over its objective. The lens and target reticle were then accurately alined, so that the axis of the lens was parallel to the bench ways, and the center of the reticle was on the optical axis of the lens. The slide carrying the target system was moved along the bench until the reticle was in the plane of best focus of the lens under test as viewed through the telescope. The $2.0-\mathrm{mm}$ diaphragm was then placed over the telescope and the center of coordinates determined. The results of measurement are shown in table 1 for five settings of the target. In this table, the target settings with respect to the lens bench scale are shown at the top; the highest numbers indicate the positions of the target nearest to the lens. The nominal values of $\Delta f$ (hereafter designated of to distinguish from the measured values of $\Delta f$ ), with respect to the plane of best focus, are shown on the next line of the table; these values are approximate as the bench scale is read with a vernier to the nearest tenth millimeter, and no attempt was made to make these settings to

TABLE 1. Variation of parallax angle, $\epsilon$, with transverse setting of telescope for five positions of the target with respect to lens 2, which has a focal length of $152.4 \mathrm{~mm}$

The column headed $\delta f=0.0$ corresponds to the position of best focus; negative values of $\delta f$ indicate the target is farther from the lens.

\begin{tabular}{|c|c|c|c|c|c|}
\hline \multirow{5}{*}{$\begin{array}{l}\text { Telescope } \\
\text { positions on } \\
\text { bench, mm }\end{array}$} & \multicolumn{5}{|c|}{ Target settings on lens bench, mm } \\
\hline & 90.1 & 90.6 & 91.1 & 91.6 & 92.1 \\
\hline & \multicolumn{5}{|c|}{ Nominal values of $\delta f, \mathrm{~mm}$} \\
\hline & -1.0 & -0.5 & 0.0 & 0.5 & 1.0 \\
\hline & \multicolumn{5}{|c|}{ Measured values of $\epsilon$, in scale divisions } \\
\hline $\begin{array}{c}\text { Left } \\
\mathrm{a} 25,3\end{array}$ & & & & & \\
\hline $\begin{array}{l}28.5 \\
28.2 \\
30.2 \\
32.2 \\
34.2\end{array}$ & $\begin{array}{l}-64.3 \\
82.2 \\
83.3 \\
78.2\end{array}$ & $\begin{array}{l}-57.3 \\
73.3 \\
75.3 \\
71.1\end{array}$ & $\begin{array}{l}-37.8 \\
62.9 \\
66.8 \\
64.4\end{array}$ & $\begin{array}{l}46.9 \\
54.2 \\
59.2 \\
58.4\end{array}$ & $\begin{array}{l}38.4 \\
46.7 \\
52.4 \\
52.8\end{array}$ \\
\hline $\begin{array}{r}36.2 \\
38.2 \\
\circ 40.2 \\
42.2 \\
44.2\end{array}$ & $\begin{array}{l}72.6 \\
67.8 \\
65.2 \\
63.5 \\
58.7\end{array}$ & $\begin{array}{l}67.3 \\
65.1 \\
64.6 \\
64.2 \\
61.9\end{array}$ & $\begin{array}{l}62.2 \\
62.2 \\
62.9 \\
64.7 \\
64.1\end{array}$ & $\begin{array}{l}58.7 \\
59.9 \\
63.0 \\
65.4 \\
66.5\end{array}$ & $\begin{array}{l}54.5 \\
58.0 \\
62.2 \\
66.6 \\
68.7\end{array}$ \\
\hline $\begin{array}{r}46.2 \\
48.2 \\
50.2 \\
52.2 \\
\text { b 55.1 } \\
\text { Right }\end{array}$ & $\begin{array}{c}53.5 \\
47.4 \\
45.8 \\
52.1 \\
-. .--\end{array}$ & $\begin{array}{r}57.9 \\
53.8 \\
54.3 \\
60.8 \\
----\end{array}$ & $\begin{array}{c}62.6 \\
60.9 \\
62.3 \\
68.9 \\
--. . .\end{array}$ & $\begin{array}{c}66.7 \\
66.7 \\
68.8 \\
76.6 \\
-\cdots-.-\end{array}$ & $\begin{array}{l}70.1 \\
72.2 \\
76.2 \\
84.1\end{array}$ \\
\hline
\end{tabular}

a First image.

b Last image.

- Center setting. better than $\pm 0.1 \mathrm{~mm}$. The left column shows the successive positions of the telescope (or pentaprism) on the transverse bench. The words, Left and Right, or $\mathrm{L}$ and $\mathrm{R}$, are included in the tables to show that the measurements are initiated at the left-hand side of the lens as viewed by the observer and are made at the designated intervals with the pentaprism being moved toward the right throughout the course of the experiment. The positions where light is first seen to enter the telescope is designated first image, and the position where it just disappears as the slide moves along the bench is designated last image. No readings of the deviation $\epsilon$ are possible at these positions, but these points serve to locate the center of coordinates, which in this instance corresponds to the $40.2-\mathrm{mm}$ setting. Observations of the deviation, $\epsilon$, are made at 2 -mm intervals along the transverse bench to a distance of $12 \mathrm{~mm}$ on each side of the central position. The values of the observed deviation are given in scale divisions for each of the five target settings. Each scale division is equivalent to 0.0283 milliradian deviation. Table 2 shows the values of $h$ and $\epsilon$ with respect to the center of coordinates; this table is derived from table 1.

TABLE 2. Variation of parallax angle, $\epsilon$, as a function of zone height, $h$, for five positions of the target with respect to the position of best focus of lens 2

This table is derived from table 1 .

\begin{tabular}{|c|c|c|c|c|c|}
\hline \multirow{3}{*}{$\begin{array}{l}\text { Zone } \\
\text { height, h, } \\
\text { mm }\end{array}$} & \multicolumn{5}{|c|}{ Nominal values of $\delta f, \mathrm{~mm}$} \\
\hline & -1.0 & -0.5 & 0.0 & 0.5 & 1.0 \\
\hline & \multicolumn{5}{|c|}{ Deviation $\epsilon$ from central position in scale divisions } \\
\hline$\stackrel{L}{L}$ & & & & & \\
\hline $\begin{array}{l}-12 \\
-10 \\
-8 \\
-6\end{array}$ & $\begin{array}{r}-0.9 \\
17.0 \\
18.1 \\
13.0\end{array}$ & $\begin{array}{r}-7.3 \\
8.7 \\
10.7 \\
6.5\end{array}$ & $\begin{array}{r}-15.1 \\
0.0 \\
3.9 \\
1.5\end{array}$ & $\begin{array}{l}-16.1 \\
-8.8 \\
-3.8 \\
-4.6\end{array}$ & $\begin{array}{l}-23.8 \\
-15.5 \\
-9.8 \\
-9.4\end{array}$ \\
\hline $\begin{array}{r}-4 \\
-2 \\
0 \\
2 \\
4\end{array}$ & $\begin{array}{r}7.4 \\
2.6 \\
0.0 \\
-1.7 \\
-6.5\end{array}$ & $\begin{array}{r}2.7 \\
0.5 \\
.0 \\
-.4 \\
-2.7\end{array}$ & $\begin{array}{r}-0.7 \\
-.7 \\
0.0 \\
1.8 \\
1.2\end{array}$ & $\begin{array}{r}-4.3 \\
-3.1 \\
0.0 \\
2.4 \\
3.5\end{array}$ & $\begin{array}{r}-7.7 \\
-4.2 \\
0.0 \\
4.4 \\
6.5\end{array}$ \\
\hline $\begin{array}{c}6 \\
8 \\
10 \\
12 \\
\text { b14. } 9 \\
R\end{array}$ & $\begin{array}{l}-11.7 \\
-17.8 \\
-19.4 \\
-13.1 \\
--.---\end{array}$ & $\begin{array}{r}-6.7 \\
-10.8 \\
-10.3 \\
-3.8 \\
----.\end{array}$ & $\begin{array}{r}-0.3 \\
-2.0 \\
-0.6 \\
6.0 \\
-\end{array}$ & $\begin{array}{r}3.7 \\
3.7 \\
5.8 \\
13.6 \\
-\cdot---\end{array}$ & $\begin{array}{r}7.9 \\
10.0 \\
14.0 \\
21.9\end{array}$ \\
\hline
\end{tabular}

a First image.

b Last image.

The variation of $\epsilon$ as a function of $h$ and $\Delta f$ for the conditions described in the preceding paragraph is shown graphically in figure 5 . It is clear that curve 3 for $\Delta f=0$ is a typical curve of angular spherical aberration, whereas the other four curves show the contribution of varying amounts of out-of-focus effect. Values of $\Delta f$ for each value of $h$ and $\epsilon$ for each target setting listed in table 2 were computed with the aid of eq (3), and the results are shown in table 3. These results are shown graphically in figure $6, A$. It is evident that the successive $\Delta f$ versus- $h$ curves are spaced along the axis of abscissas with separations closely approximating the 


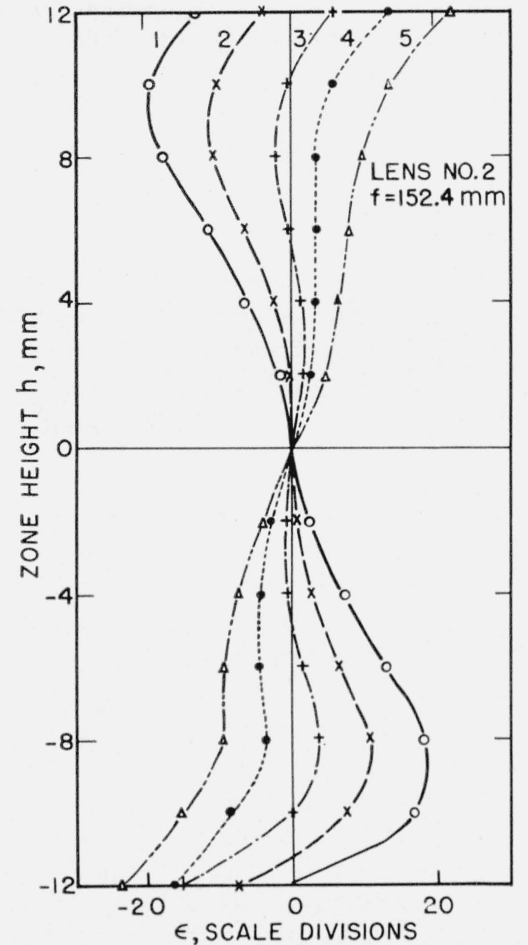

Figure 5. Curves of parallax angle, $\epsilon$, versus zone height, $h$, for lens 2 showing the effect of successive target displacements of approximately $0.5 \mathrm{~mm}$ along the axis.

The results for a target position $1.0 \mathrm{~mm}$ farther from the lens than the plane of best focus are shown in curve 1 . Curve 5 shows the results for a target position $1.0 \mathrm{~mm}$ nearer to the lens than the plane of best focus. Curves 2, 3 , and 4 show the results for intermediate position (see tables 1 and 2 ).

TABLE 3. Computed values of $\Delta f$ as a function of zone height, $h$, for five positions of the target with respect to the position of best focus for lens 2 (see tables 1 and 2$)$

The value of focal length, $f$, is $152.4 \mathrm{~mm}$. In converting $\epsilon$ in scale divisions to $\epsilon$ in milliradians, 1 scale division $=0.0283$ milliradian.

\begin{tabular}{|c|c|c|c|c|c|}
\hline \multirow{3}{*}{$\begin{array}{c}\text { Zone } \\
\text { height, } \\
h, \mathrm{~mm}\end{array}$} & \multicolumn{5}{|c|}{ Nominal values of $\delta f, \mathrm{~mm}$} \\
\hline & -1.0 & -0.5 & 0.0 & 0.5 & 1.0 \\
\hline & \multicolumn{5}{|c|}{ Computed values of $\Delta f, \mathrm{~mm}$} \\
\hline $\begin{array}{l}L \\
-12 \\
-10 \\
-8 \\
-6\end{array}$ & $\begin{array}{r}0.05 \\
-1.12 \\
-1.49 \\
-1.42\end{array}$ & $\begin{array}{r}0.40 \\
-.57 \\
-.88 \\
-.71\end{array}$ & $\begin{array}{r}0.83 \\
.00 \\
-.32 \\
-.16\end{array}$ & $\begin{array}{r}0.88 \\
.58 \\
.31 \\
.50\end{array}$ & $\begin{array}{l}1.30 \\
1.02 \\
0.81 \\
1.03\end{array}$ \\
\hline $\begin{array}{l}-4 \\
-2\end{array}$ & $\begin{array}{l}-1.22 \\
-0.86\end{array}$ & $\begin{array}{l}-.44 \\
-.16\end{array}$ & $\begin{array}{l}.12 \\
.23\end{array}$ & $\begin{array}{r}.71 \\
1.02\end{array}$ & $\begin{array}{r}.127 \\
1.38\end{array}$ \\
\hline $\begin{array}{l}0 \\
2 \\
4\end{array}$ & $\begin{array}{l}-0.56 \\
-1.07\end{array}$ & $\begin{array}{r}-.13 \\
-.44\end{array}$ & $\begin{array}{l}.59 \\
.20\end{array}$ & $\begin{array}{r}0.79 \\
.58\end{array}$ & $\begin{array}{l}1.45 \\
1.07\end{array}$ \\
\hline $\begin{array}{r}6 \\
8 \\
10 \\
12 \\
R\end{array}$ & $\begin{array}{l}-1.28 \\
-1.46 \\
-1.28 \\
-0.72\end{array}$ & $\begin{array}{l}-.73 \\
-.89 \\
-.68 \\
-.21\end{array}$ & $\begin{array}{r}-.03 \\
-.16 \\
-.04 \\
.33\end{array}$ & $\begin{array}{l}.41 \\
.30 \\
.38 \\
.74\end{array}$ & $\begin{array}{r}0.87 \\
.82 \\
.92 \\
1.20\end{array}$ \\
\hline
\end{tabular}

nominal intervals separating successive positions of the target. The large negative values of $\Delta f$ are associated with negative values of the nominal $\delta f$, so that eq (3) evidently gives the correct sign of the displacement with respect to the lens.
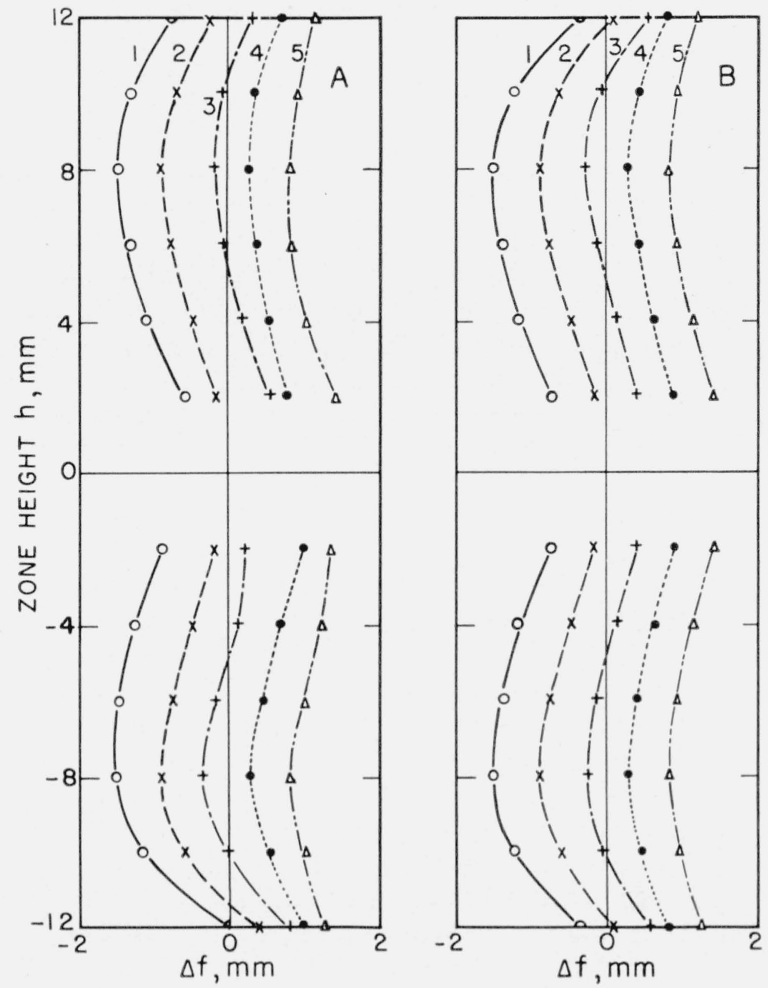

Figure 6. $\Delta f$ versus $h$ curves for a series of target positions.

A. Values of the displacement from best focus, $\Delta f$, as a function of zone height, $h$, for the conditions shown in figure 5 (see table 3 ).

B. Averaged values of $\Delta f$ versus $h$, derived from part A (see table 4).

TABLE 4. Average values of $\Delta f$ as a function of zone height, $h$, for five positions of the target with respect to the position of best focus for lens 2.

These results are derived from table 3 .

\begin{tabular}{|c|c|c|c|c|c|}
\hline & \multicolumn{5}{|c|}{ Nominal values of $\delta f, \mathrm{~mm}$} \\
\cline { 2 - 5 } $\begin{array}{c}\text { Zone } \\
\text { height, } \\
h\end{array}$ & -1.0 & -0.5 & 0.0 & 0.5 & 1.0 \\
\cline { 2 - 5 } & \multicolumn{5}{|c|}{ Average measured value of $\Delta f, \mathrm{~mm}$} \\
\hline \multirow{2}{*}{\begin{tabular}{c|c|c|c|c|} 
\\
2
\end{tabular}} & -0.71 & -0.14 & 0.41 & 0.90 & 1.42 \\
4 & -1.14 & -.44 & .16 & .64 & 1.17 \\
6 & -1.35 & -.72 & -.10 & .46 & 0.95 \\
8 & -1.48 & -.88 & -.24 & .30 & .82 \\
10 & -1.20 & -.62 & -.02 & .48 & .97 \\
12 & -0.34 & +.10 & +.58 & .81 & 1.25 \\
\hline
\end{tabular}

The curves shown in figure $6, \mathrm{~A}$ are not completely symmetrical about the axis but can be made so by averaging the values of $\Delta f$ at corresponding values of $+h$ and $-h$. The resulting values of $\Delta f$ given in table 4 are shown graphically in figure $6, B$. The curve for nominal $\delta f=0$ is the normal longitudinal spherical aberration curve for the lens with respect to the plane of best focus for a zone height, $h=10 \mathrm{~mm}$. 


\section{b. Sources of Error}

When the averaged values of $\Delta f$ given in table 4 are compared with the initial values shown in table 3 , it is clear that the departures of the individual values from the average value tend to vary somewhat with $h$. This is shown in table 5 , where the departures of the initial values of $\Delta f$ from the average are listed for each value of $h$ and nominal $\delta f$. The average departures for the five values of nominal $\delta f$ are also given in the table. It is noteworthy that the average variation for zones $4,6,8$, and 10 are of the order of $\pm 0.05 \mathrm{~mm}$, whereas the variation is $\pm 0.10 \mathrm{~mm}$ for zone 2 and \pm 0.21 for zone 12 . A small error in the location of the zero position of $h$ on the transverse bench scale will produce appreciable asymmetries in the initial values of $\epsilon$ and $\Delta f$; the values will tend to be too high on one side and too low to about the same degree on the other. However, this type of error does not affect the final average value to an appreciable extent. Errors in $\Delta f$ arising from errors in $h$ are proportional to the fractional error in $h$; thus an error of $\pm 0.1 \mathrm{~mm}$ produces a 5 -percent error in $\Delta f$ for $h=2 \mathrm{~mm}$, but only a 1 -percent error in $\Delta f$ for $h=10 \mathrm{~mm}$. Similarly errors in $\epsilon$ are more serious for small values of $h$. For the case under consideration, an error in $\epsilon$ of \pm 0.1 scale division produces an error of $\pm 0.03 \mathrm{~mm}$ in $\Delta f$ for $h=2 \mathrm{~mm}$ and an error of $\pm 0.01 \mathrm{~mm}$ in $\Delta f$ for $h=6 \mathrm{~mm}$. The large errors at $h=12 \mathrm{~mm}$ are caused by asymmetrical use of the 2-mm viewing aperture at the edge of the lens.

TABLE 5. Departures of measured values of $\Delta f$ at paired values of the zone height, $h$, from the average value of $\Delta f$ for each value of $h$ for five positions of the target with respect to the position of best focus.

The average variation for each zone is also given. These results are for lens 2 and are derived from tables 3 and 4 .

\begin{tabular}{|c|c|c|c|c|c|c|}
\hline \multirow{3}{*}{$\begin{array}{c}\text { Zone } \\
\text { height, } \\
h\end{array}$} & \multicolumn{6}{|c|}{ Nominal values of $\delta f, \mathrm{~mm}$} \\
\hline & -1.0 & -0.5 & 0.0 & 0.5 & 1.0 & \multirow{2}{*}{$\begin{array}{l}\text { Average } \\
\text { departure }\end{array}$} \\
\hline & \multicolumn{5}{|c|}{ Departures of initial values of $\Delta f$ from average, $\mathrm{mm}$} & \\
\hline $\begin{array}{r}m m \\
2 \\
4 \\
6 \\
8 \\
10\end{array}$ & $\begin{array}{r} \pm 0.15 \\
.08 \\
.07 \\
.01 \\
.08\end{array}$ & $\begin{array}{r} \pm 0.02 \\
.00 \\
.01 \\
.00 \\
.05\end{array}$ & $\begin{array}{r} \pm 0.18 \\
.04 \\
.06 \\
.08 \\
.02\end{array}$ & $\begin{array}{r} \pm 0.12 \\
.07 \\
.04 \\
.01 \\
.10\end{array}$ & $\begin{array}{r} \pm 0.04 \\
.10 \\
.08 \\
.01 \\
.05\end{array}$ & $\begin{array}{c}m m \\
\pm 0.10 \\
.06 \\
.05 \\
.02 \\
.06\end{array}$ \\
\hline 12 & .39 & .30 & .25 & .07 & .05 & .21 \\
\hline
\end{tabular}

It is of interest to compare the values of $\Delta f$ obtained for each zone with each other and with the nominal vaues of $\delta f$ through which the target is displaced. This comparison is given in table 6 , where the difference in $\Delta f$ for each zone from the value for $\Delta f=0$ is given. It is clear that the successive values compare quite favorably with each other for zones 2 through 10. It is, therefore, clear that quite reliable values of $\Delta f$ are obtained by this procedure, and it appears probable that the values of the longitudinal spherical aberration so obtained are reliable to $\pm 0.04 \mathrm{~mm}$ for this particular lens.
TABLE 6. Computed values of the separations of the target from the position of best focus for lens 2 .

These results are derived from table 4.

\begin{tabular}{|c|c|c|c|c|c|}
\hline \multirow{3}{*}{ Zone height, $h$} & \multicolumn{5}{|c|}{ Nominal values of $\delta f, \mathrm{~mm}$} \\
\hline & -1.0 & -0.5 & 0.0 & 0.5 & 1.0 \\
\hline & \multicolumn{5}{|c|}{ A verage measured value of $\Delta f, \mathrm{~mm}$} \\
\hline$m m$ & & & & & \\
\hline 2 & -1.12 & -0.55 & 0.00 & 0.49 & 1.01 \\
\hline 4 & -1.30 & -.60 & .00 & .48 & 1.01 \\
\hline 6 & -1.25 & -.62 & .00 & .56 & 1.05 \\
\hline 8 & -1.24 & -.64 & .00 & .54 & 1.06 \\
\hline 10 & -1.18 & -60 & .00 & .50 & 0.99 \\
\hline \multirow{2}{*}{$\begin{array}{l}12 \\
\text { A verage (2 through } \\
\text { 10) }\end{array}$} & -0.92 & -.48 & .00 & .23 & .67 \\
\hline & -1.22 & -0.60 & 0.00 & 0.51 & 1.02 \\
\hline
\end{tabular}

4.2. Longitudinal Chromatic Aberration of a Telescope Objective Having a Focal Length of 120 Millimeters

The axial longitudinal spherical aberration of a lens usually varies with the wavelength of the imageforming light. Thus if the longitudinal spherical aberration is measured for two different colors of light, the characteristic curves of $\Delta f$ versus $h$ will be displaced along the axis with respect to each other. The method of measurement described in section 4.1 provides a simple method of determining not only the longitudinal spherical aberration curve for a given color but also the displacement zone by zone for differing colors. To illustrate this, results of measurement are given for a lens, designated 3, having a focal length of $120 \mathrm{~mm}$ and a clear aperture of $40 \mathrm{~mm}$.

The same procedure was followed as outlined in section 4.1 except that three successive runs were made. For each run, a different filter was placed between the light source and the target. In the present instance Wratten monochromatic filters 74 (green), 75 (blue green), and 70 (red) were used, and the results of measurement of parallax angle, $\epsilon$, as a function of zone height, $h$, are shown in table 7. The variation of $\epsilon$ with $h$ is shown graphically in figure $7, \mathrm{~A}$ for each of the three colors. The values of $\Delta f$ computed for each value of $h$ are likewise shown in table 7 , and the averaged values of $\Delta f$ for paired values of $h$ are shown graphically in figure $7, \mathrm{~B}$. The position of the target was left unchanged during the entire experiment, consequently the $\Delta f$-versus- $h$ curves in figure $7, B$, show both the longitudinal spherical aberration and the longitudinal chromatic aberration. It is noteworthy that the chromatic difference in focus between the light passed by filters 74 and 75 is negligibly small, whereas the difference for 74 and 70 is appreciable. Some out-of-focus effect is present, which shows that the target was approximately $0.27 \mathrm{~mm}$ farther from the lens than the position of best focus for filter 74 . It can be inferred from the average values of $\Delta f$, shown in table 7 , that the chromatic difference in focal length between the light passed by filters 74 and 75 is $0.03 \mathrm{~mm}$ and between filters 74 and 70 is $0.10 \mathrm{~mm}$. 
TABLE 7. Variation of parallax angle, $\epsilon$, and $\Delta f$ as a function of zone height, $h$, for three colors ( 74 green, 75 blue green, and 70 red)

The results are for lens 3 , a telescope objective having a focal length of $120 \mathrm{~mm}$.

\begin{tabular}{|c|c|c|c|c|c|c|}
\hline \multirow{3}{*}{$\begin{array}{c}\text { Zone } \\
\text { height, } h\end{array}$} & \multicolumn{6}{|c|}{ Filter number } \\
\hline & \multicolumn{2}{|c|}{74} & \multicolumn{2}{|c|}{75} & \multicolumn{2}{|c|}{70} \\
\hline & $\begin{array}{c}\epsilon \text {, scale } \\
\text { divisions }\end{array}$ & $\Delta f$ & $\begin{array}{c}\epsilon \text {, scale } \\
\text { divisions }\end{array}$ & $\Delta f$ & $\begin{array}{c}\epsilon \text {, scale } \\
\text { divisions }\end{array}$ & $\Delta f$ \\
\hline $\begin{array}{c}m m \\
-20 \\
-16 \\
-12 \\
-8\end{array}$ & $\begin{array}{r}15.3 \\
11.9 \\
7.6 \\
4.8\end{array}$ & $\begin{array}{c}m m \\
-0.31 \\
-.30 \\
-.26 \\
-.24\end{array}$ & $\begin{array}{r}12.5 \\
9.7 \\
6.6 \\
4.1\end{array}$ & $\begin{array}{c}m m \\
-0.26 \\
-.25 \\
-.22 \\
-.21\end{array}$ & $\begin{array}{r}15.9 \\
9.0 \\
4.4 \\
2.4\end{array}$ & $\begin{array}{c}m m \\
-0.32 \\
-.23 \\
-.15 \\
-.12\end{array}$ \\
\hline $\begin{array}{r}-4 \\
-2 \\
0 \\
2 \\
4\end{array}$ & $\begin{array}{r}2.5 \\
1.2 \\
0 \\
-1.3 \\
-2.5\end{array}$ & $\begin{array}{r}-.26 \\
-.24 \\
-.26 \\
-.26\end{array}$ & $\begin{array}{r}2.3 \\
1.1 \\
0 \\
-1.3 \\
-2.5\end{array}$ & $\begin{array}{r}-.23 \\
-.22 \\
-.26 \\
-.26\end{array}$ & $\begin{array}{l}1.4 \\
0.6 \\
0 \\
-.5 \\
-.9\end{array}$ & $\begin{array}{r}-.14 \\
-.12 \\
-.10 \\
-.09\end{array}$ \\
\hline $\begin{array}{r}8 \\
12 \\
16 \\
20\end{array}$ & $\begin{array}{r}-4.9 \\
-7.7 \\
-12.0 \\
-16.4\end{array}$ & $\begin{array}{l}-.25 \\
-.26 \\
-.31 \\
-.33\end{array}$ & $\begin{array}{r}-4.9 \\
-7.1 \\
-11.0 \\
-13.8\end{array}$ & $\begin{array}{l}-.25 \\
-.24 \\
-.28 \\
-.28\end{array}$ & $\begin{array}{r}-2.4 \\
-4.8 \\
-8.7 \\
-13.1\end{array}$ & $\begin{array}{l}-.12 \\
-.16 \\
-.22 \\
-.27\end{array}$ \\
\hline Average.. & ....... & -0.27 & ....... & -0.24 & -...-. & -0.17 \\
\hline
\end{tabular}

\subsection{Telescope Objective Having a Focal Length of 167 Millimeters}

In the course of making measurements on lenses of various types and focal lengths, one occasionally finds effects that are of unusual interest. The results of measurement of longitudinal spherical aberration on this lens are here included because of the unusual form of the longitudinal spherical aberration curve. The lens, designated 4 , is a telescope objective having a focal length of $167 \mathrm{~mm}$ and a clear aperture of approximately $46 \mathrm{~mm}$.

The test procedure was essentially the same as that described in section 4.2, except that only two filters, 74 and 70 , were used. The data for filter 75 are omitted, as the results obtained with it are nearly identical with those for filter 74 . The results of measurement of parallax angle, $\epsilon$, as a function of zone height, $h$, are shown in table 8 and figure $8, \mathrm{~A}$. The values of $\Delta f$ were computed for each value of $h$ and are shown in table 8 . The averaged values of $\Delta f$ for paired values of $h$ are shown graphically in figure $8, \mathrm{~B}$. The curves in figure $8, \mathrm{~B}$ show the longitudinal spherical aberration for each of two colors. It is noteworthy that the two curves are similar but are separated from each other by approximately $0.2 \mathrm{~mm}$.

It is interesting to note the shape of the $\Delta f$ versus $h$ curves in figure $8, B$. In the vicinity of the axis, the curves have a bulge toward the direction of shorter focal length. This anomaly does not occur in all lenses measured, but it does occur in enough to create a belief that this effect does not arise from experimental error. It is possible that it may result from a variation in the radius of curvature of one of the components of the lens under test.
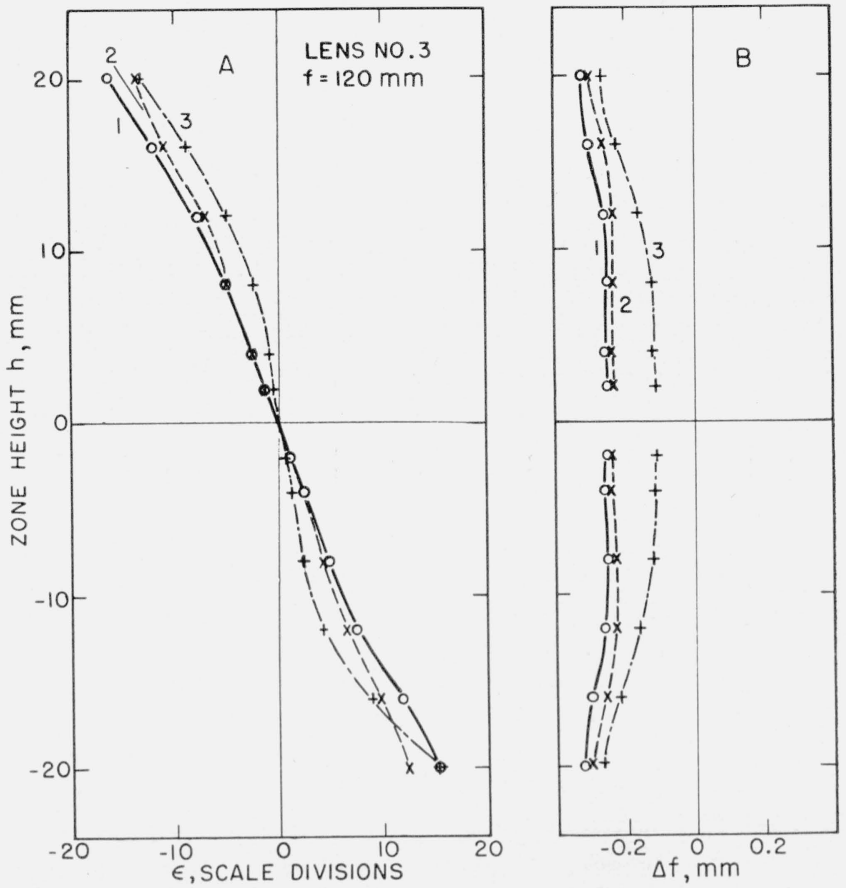

Figure 7. Parallax angle $\epsilon$ versus $h$, and $\Delta f$ versus $h$ for three colors.

A. The values of parallax angle $\epsilon$, as a function of zone height $h$, are given in curves 1, 2, and 3, for Wratten filters 74 (green), 75 (blue green), and 70 (red), respectively.

B. Values of longitudinal chromatic and spherical aberration $\Delta$ f derived from the measurements shown in part A (and table 7).

TABLE 8. Variation of parallax angle, $\epsilon$, and $\Delta f$ as a function of zone height, $h$, for two colors ( 74 green and 70 red)

The results are for lens 4, a telescope objective having a focal length of $166.7 \mathrm{~mm}$.

\begin{tabular}{|c|c|c|c|c|}
\hline \multirow{3}{*}{$\begin{array}{c}\text { Zone } \\
\text { height, } \\
h\end{array}$} & \multicolumn{4}{|c|}{ Filter number } \\
\hline & \multicolumn{2}{|c|}{74} & \multicolumn{2}{|c|}{70} \\
\hline & $\begin{array}{c}\epsilon \text {, scale } \\
\text { divisions }\end{array}$ & $\Delta f$ & $\begin{array}{l}\epsilon \text {, scale } \\
\text { divisions }\end{array}$ & $\Delta f$ \\
\hline $\begin{array}{l}m m \\
-23 \\
-21.5 \\
-20 \\
-15 \\
-10\end{array}$ & $\begin{array}{r}12.2 \\
8.1 \\
5.6 \\
2.8 \\
1.6\end{array}$ & $\begin{array}{c}m m \\
-0.42 \\
-.30 \\
-.22 \\
-.15 \\
-.13\end{array}$ & $\begin{array}{r}10.1 \\
5.8 \\
2.7 \\
-1.4 \\
-2.2\end{array}$ & $\begin{array}{c}m m \\
-0.34 \\
-.21 \\
-. .11 \\
+.07 \\
.17\end{array}$ \\
\hline $\begin{array}{l}-7.5 \\
-5\end{array}$ & $\begin{array}{l}1.3 \\
1.5\end{array}$ & $\begin{array}{l}-.14 \\
-.24\end{array}$ & $\begin{array}{l}-1.7 \\
-0.9\end{array}$ & $\begin{array}{l}.18 \\
.14\end{array}$ \\
\hline-2.5 & $\begin{array}{l}0.8 \\
0\end{array}$ & -.25 & -.4 & .13 \\
\hline 2.5 & -.7 & -22 & .2 & .06 \\
\hline 7.5 & $\begin{array}{l}-1.0 \\
-1.2\end{array}$ & -.13 & 1.5 & .16 \\
\hline $\begin{array}{l}10 \\
15\end{array}$ & $\begin{array}{l}-1.3 \\
-2.1\end{array}$ & $\begin{array}{l}-.10 \\
-.11\end{array}$ & $\begin{array}{l}2.5 \\
1.9\end{array}$ & $\begin{array}{l}.20 \\
10\end{array}$ \\
\hline 200 & $\begin{array}{l}-4.3 \\
-6.5\end{array}$ & $\begin{array}{r}-17 \\
-.24\end{array}$ & $\begin{array}{l}-2.2 \\
-2.2\end{array}$ & $\begin{array}{l}-09 \\
-.09 \\
-18\end{array}$ \\
\hline 23 & $\begin{array}{l}-6.0 \\
-9.4\end{array}$ & $\begin{array}{l}-.24 \\
-.32\end{array}$ & $\begin{array}{l}-4.8 \\
-7.2\end{array}$ & +.25 \\
\hline A verage. & -..-.-. & -0.22 & -..-... & +0.01 \\
\hline
\end{tabular}



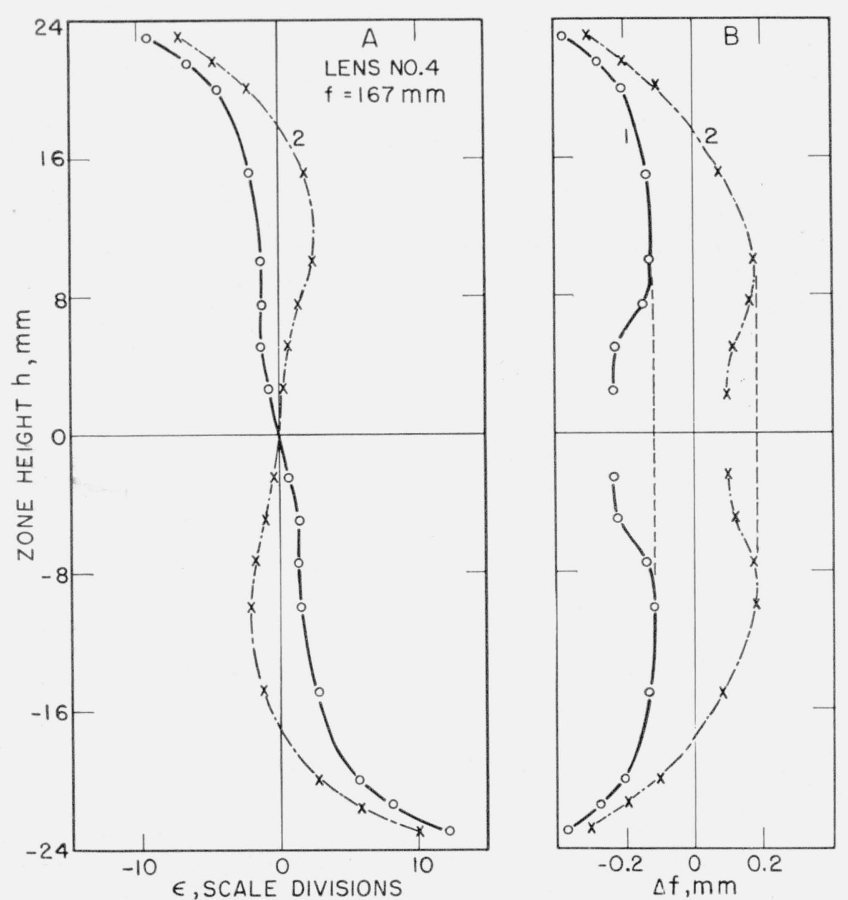

Figure 8. Curves for a lens showing unusual characteristics of the longitudinal spherical aberration obtained for two colors.

Curve 1 shows the results for Wratten No. 74 filter, and curve 2 shows the results for Wratten No. 70 filter. The curves appear to bulge in an unusual fashion away from the lens in the axial region (see table 8).

\section{Sources of Error}

In section 2 , it is noted that an error in the location of the target reticle with respect to the focal point of the lens would produce an error in the measured values of the parallax angle, $\epsilon$, and that this error would be propagated into the computation of those values of $\Delta f$ from which the values of the longitudinal spherical aberration are derived. It is, however, a simple matter to so position the reticle that variations in the value of $\Delta f$ from this cause are less than 1 percent and can be regarded as negligible. It is worthwhile to consider the magnitude of the errors induced in $\Delta f$ by errors in the measured values of the zone height, $h$, and the parallax angle, $\epsilon$. The effect of errors in $h$ and $\epsilon$ are discussed briefly in section $4.1, \mathrm{~b}$ in connection with the measurements on a particular lens, but some additional comments are given in the following sections.

\subsection{Effect of Error in the Values of $h$}

There are two potential sources of error in the determination of the zone height, $h$. If the values of $h$ are measured accurately but with respect to an incorrect zero position, the curve of $\epsilon$ versus $h$ is not symmetric about the origin and creates the appearance of large error. This is particularly noticeable in the derived curve of $\Delta f$ versus $h$, as it produces a very pronounced asymmetry. This error may be minimized or eliminated by averaging the values of
$\Delta f$ for corresponding values of $t h$ and $-h$. It is usually, however, more aesthetically satisfying to make a more accurate determination of the correct zero position and to make the computations with respect to this corrected position.

When the values of $h$ are measured with respect to the correct zero position, then the values of $\Delta f$ are affected by a given fractional error in $h$ by approximately the same fractional error. Thus for a constant error in $h$, the fractional error increases with decreasing $h$ and so places a lower limit on the value of $h$ that may be profitably used. Assuming that $h$ can be measured to the nearest $\pm 0.05 \mathrm{~mm}$, the lowest value of $h$ that can be used is $\pm 1.0 \mathrm{~mm}$ if one does not wish the error in $\Delta f$ from this source to exceed 5 percent. For the same constant error in $h$, the error in $\Delta f$ at $h= \pm 10 \mathrm{~mm}$ is \pm 0.5 percent, which may usually be regarded as negligible.

\subsection{Effect of Errors in $\epsilon$}

The magnitude of the observed parallax angle, $\epsilon$ is usually quite small, so that errors in $\epsilon$ provide the primary limitation in the determination of $\Delta f$. It is difficult to determine $\epsilon$ with an accuracy better than \pm 0.5 sec because of limitations placed by pointing accuracy. ${ }^{2}$ It is probable that determinations of $\epsilon$ can be made by using reasonable care, so that the error of the mean does not exceed \pm 1.0 sec. For purposes of illustration, computations of the magnitude of the error in $\Delta f$ caused by an error of $\pm 2.0 \mathrm{sec}$ were made for a series of values of equivalent focal length, $f$, and the zone height, $h$, and the results are shown in table 9, A. In these computations, the equation

$$
\Delta f=\epsilon \frac{f^{2}}{h}
$$

was used, with value of $\epsilon$ maintained constant at \pm 2 sec. Consideration of the values in part $A$ of table 9 makes it clear that the magnitude of the error in $\Delta f$ increases steadily with $f$ for a fixed value of $h$, and inversely with $h$ for a fixed value of $f$. For values of $f$ above $100 \mathrm{~mm}$, the errors in $\Delta f$ become appreciable for the selected value of the error in $\epsilon$. It is, therefore, interesting to consider these magnitudes of the error in $\Delta f$ with the theoretical depth of focus, $d_{f}$, of a lens in the image space. Approximate values of $d_{f}$ in millimeters are computed on the basis of the equation

$$
d_{f}=\frac{4 b}{R_{m}}
$$

where $b$ is the $f$-number and $R_{m}$ is the maximum theoretical resolving power for light having a wavelength of $575 \mathrm{~m} \mu .^{3}$ The value of $R_{m}$ in lines per millimeter can be computed with the aid of the formula

$$
R_{m}=\frac{1426}{b} .
$$

2 F. E. Washer, Effect of magnification on the precision of indoor telescope pointing, J. Research NBS 39, 163 (1947) RP1820.

3 F. E. Washer, Region of usable imagery in airplane-camera lenses, J. Research NBS 34, 175 (1945) RP1636. 
TABLE 9. Effect of errors on the determination of longitudinal spherical aberration

Comparison of the error produced in the determination of the longitudinal spherical aberration, $\Delta f$, by an error of \pm 2 sec in the measured value of the parallax angle, $\epsilon$, with the theoretical depth of focus in the image space, $d_{f}$, that yields maximum theoretical resolving power, $R_{m}$, for light having a wavelength of maximu $\mathrm{m} \mu$.

$575 \mathrm{~m} \mu$.
Values are given in millimeters for a series of values of equivalent focal length $f$, and zone height, $h$.

\begin{tabular}{|c|c|c|c|c|c|}
\hline \multirow{2}{*}{$\begin{array}{l}\text { Zone } \\
\text { height, } \\
h\end{array}$} & \multicolumn{5}{|c|}{$\begin{array}{l}\text { A. Errors produced in the longitudinal spherical aberration, } \\
\Delta f, \text { by an error of } \pm 2 \text { seconds for various values of } f\end{array}$} \\
\hline & 50 & 100 & 200 & 400 & 800 \\
\hline \multirow[t]{3}{*}{$\begin{array}{c}m m \\
2.5 \\
5 \\
10 \\
20 \\
40\end{array}$} & $\begin{array}{r} \pm 0.010 \\
.005 \\
.002 \\
\end{array}$ & $\begin{array}{r} \pm 0.039 \\
.019 \\
.010 \\
.005 \\
\end{array}$ & $\begin{array}{r} \pm 0.155 \\
.078 \\
.039 \\
.019 \\
.010\end{array}$ & $\begin{array}{r} \pm 0.62 \\
.31 \\
.16 \\
.08 \\
.04\end{array}$ & $\begin{array}{r} \pm 2.49 \\
1.24 \\
0.62 \\
.32 \\
.16\end{array}$ \\
\hline & \multicolumn{5}{|c|}{$\begin{array}{l}\text { B. Values of theoretical total depth of focus, } d_{f} \text {, yielding a } \\
\text { resolving power } R_{m} \text { for the following values of } f\end{array}$} \\
\hline & 50 & 100 & 200 & 400 & 800 \\
\hline $\begin{array}{l}2.5 \\
5 \\
10 \\
20 \\
40\end{array}$ & $\begin{array}{r}0.280 \\
.070 \\
.018 \\
\end{array}$ & $\begin{array}{r}1.120 \\
.280 \\
.070 \\
.018 \\
\end{array}$ & $\begin{array}{r}4.48 \\
1.12 \\
0.28 \\
.07 \\
.02\end{array}$ & $\begin{array}{r}17.92 \\
4.48 \\
1.12 \\
0.28 \\
.07\end{array}$ & $\begin{array}{r}71.7 \\
17.9 \\
4.5 \\
1.1 \\
0.3\end{array}$ \\
\hline
\end{tabular}

It must be mentioned that values of $d_{f}$ obtained with eq (4) are for an ideal lens; for an actual lens having aberrations the value of $d_{f}$ may range from approximately $2.8 b / R_{m}$ to $4 b / R_{m}$.

To facilitate the computation of $d_{f}$, the values of the $f$-number, $b$, and the maximum theoretical resolving power are shown in table 10 for each value of the zone height, $h$, and equivalent focal length, $f$, shown in table $9, A$. The values of $d_{f}$ are computed with the aid of eq (4), and the resulting values are shown in part B of table 9 for ready comparison with the errors in $\Delta f$ shown in part $A$ of the same table. It is readily seen that the values of errors in $\Delta f$ (or $\delta \Delta f$ ) are quite small in comparison with $d_{f}$ for small values of $h$. The relation can be shown to be

$$
\delta \Delta f=0.014 h d_{f}
$$

indicating that the relative magnitude of $\delta \Delta f$ with respect to $d_{f}$ is independent of the focal length, $f$, but does increase with increasing $h$. From these considerations, it is evident that although the error in $\Delta f$ is large at small values of $h$, these large errors are small in comparison with the usable depth of focus, $d_{f}$. In addition, $\delta \Delta f$ becomes small with large values of $h$, thus compensating for the increase in relative magnitude of $\delta \Delta f$ with respect to $d_{f}$ for large values of $h$.
TABLE 10. Values of the f-number, $b$, and maximum theoretical values of the resolving power, $R_{m}$, used in computing the values of $d_{f}$ shown in part $B$ of table 9

\begin{tabular}{|c|c|c|c|c|c|}
\hline \multirow{2}{*}{$\begin{array}{c}\text { Zone } \\
\text { height } \\
h\end{array}$} & \multicolumn{5}{|c|}{$\begin{array}{l}\text { A. Values of } f \text {-number, } b \text {, corresponding to successive zones } \\
\text { for the following values of } f\end{array}$} \\
\hline & 50 & 100 & 200 & 400 & 800 \\
\hline \multirow[t]{3}{*}{$\begin{array}{c}m m \\
2.5 \\
5 \\
10 \\
20 \\
40\end{array}$} & $\begin{array}{c}10 \\
5 \\
2.5 \\
-.-. \\
\end{array}$ & $\begin{array}{c}20 \\
10 \\
5 \\
2.5\end{array}$ & $\begin{array}{c}40 \\
20 \\
10 \\
5 \\
2.5\end{array}$ & $\begin{array}{r}80 \\
40 \\
20 \\
10 \\
5\end{array}$ & $\begin{array}{r}160 \\
80 \\
40 \\
20 \\
10\end{array}$ \\
\hline & \multicolumn{5}{|c|}{$\begin{array}{l}\text { B. Values of maximum theoretical resolving power, } R_{m} \text {, in } \\
\text { lines per millimeter for } \lambda=575 \mathrm{~m} \mu \text {, for the following values of } f\end{array}$} \\
\hline & 50 & 100 & 200 & 400 & 800 \\
\hline $\begin{array}{c}2.5 \\
5 \\
10 \\
20 \\
40\end{array}$ & \begin{tabular}{c}
143 \\
286 \\
572 \\
\hdashline-0. \\
\end{tabular} & $\begin{array}{r}72 \\
143 \\
286 \\
572 \\
-.--\end{array}$ & $\begin{array}{r}36 \\
72 \\
143 \\
286 \\
572\end{array}$ & $\begin{array}{r}18 \\
36 \\
72 \\
143 \\
286\end{array}$ & $\begin{array}{r}9 \\
18 \\
36 \\
72 \\
143\end{array}$ \\
\hline
\end{tabular}

\section{Discussion}

This method of measuring longitudinal spherical aberration and longitudinal chromatic aberration has been used at the Bureau for some time. It has been used for lenses having focal lengths ranging from $2 \mathrm{in}$. to $15 \mathrm{ft}$. and having apertures ranging from 0.5 in. to 12 in. It has an accuracy comparable to the Hartmann photographic test method.4 It has the advantage of being a visual test method. It can, moreover, provide reasonably accurate values quickly and easily.

The author expresses his appreciation to other members of the staff of the National Bureau of Standards for assistance during this work. Some of the measurements were made by Walter R. Darling.

4 J. Hartmann, Z. Instrumentenk. 24, 1, 33, 97 (1904).

Washington, February 26, 1958. 